\title{
A relação conjugal na perspectiva de casais
}

\section{The marital relationship from the perspective of couples}

\section{La relación conyugal desde la perspectiva de las parejas}

\author{
Marina Zanella Delatorre ${ }^{1}$, ORCID 0000-0002-8475-6213 \\ Adriana Wagner ${ }^{2}$, ORCID 0000-0003-0201-5516 \\ ${ }^{12}$ Universidade Federal do Rio Grande do Sul. Brasil
}

\begin{abstract}
Resumo: As relações conjugais têm sido amplamente estudadas, porém, há pouca clareza sobre a abrangência, a definição e a contextualização teórica do conceito de qualidade conjugal. Assim, este estudo buscou aclarar o construto de qualidade conjugal propondo dimensões que elucidem a intersecção de a temas relativos ao indivíduo, ao contexto e os processos adaptativos, na perspectiva de casais. Oito casais responderam a uma entrevista semiestruturada sobre o relacionamento conjugal que foi submetida a uma análise temática. Foram identificados 21 temas, divididos em 4 eixos constitutivos do modelo: indivíduo, contexto, processos adaptativos e qualidade conjugal. Os processos adaptativos tiveram papel central, sendo que as relações entre os eixos indivíduo e contexto e o eixo qualidade conjugal perpassam esses processos. Ressalta-se a importância dos processos adaptativos nas intervenções com casais e recomenda-se que a pertinência do modelo adotado continue sendo investigada no Brasil.
\end{abstract}

Palavras-chave: relações conjugais, casamento, qualidade conjugal, indivíduo, contexto

Abstract: Marital relationships have been widely investigated. However, there is little clarity about the definition, theoretical contextualization, and the comprehensiveness of the concept of marital quality. Thus, this study aimed to clarify the marital quality construct by proposing dimensions that elucidate an intersection of themes related to the individual, the context, and the adaptive processes, from the perspective of couples. Eight couples answered a semi-structured interview on their marital relationship, which was examined through a thematic analysis. Twenty-one themes were identified, divided into four thematic axes based on the model: individual, context, adaptive processes, and marital quality. Adaptive processes played a central role, as the relationships between the individual and the context axes with the marital quality axis permeate these processes. The importance of adaptive processes in couple interventions is emphasized and further investigation of the adopted model in Brazil is recommended.

Keywords: marital relations, marriage, marital quality, individuality, context 
Resumen: Las relaciones conyugales han sido ampliamente investigadas, sin embargo, hay poca claridad sobre el alcance, definición y contextualización teórica del concepto de calidad conyugal. Así, este estudio buscó aclarar el constructo calidad conyugal proponiendo dimensiones que elucidan la intersección de temas relacionados con el individuo, el contexto y los procesos adaptativos, desde la perspectiva de las parejas. Ocho parejas respondieron a una entrevista semiestructurada sobre la relación matrimonial, la cual se sometió a un análisis temático. Se identificaron veintiún temas, divididos en cuatro ejes basados en el modelo: individuo, contexto, procesos de adaptación y calidad conyugal. Los procesos de adaptación jugaron un rol central, y las relaciones entre los ejes individuo y contexto y los ejes de calidad conyugal permean estos procesos. Se enfatiza la importancia de los procesos de adaptación en las intervenciones con parejas y se recomienda seguir investigando en Brasil el modelo adoptado debido a su relevancia.

Palabras clave: relaciones conyugales, matrimonio, calidad conyugal, individuo, contexto

Recebido: 06/08/2019

Aceito: $20 / 10 / 2020$

\section{Como citar:}

Delatorre, M. Z., \& Wagner, A. (2021). A relação conjugal na perspectiva de casais. Ciencias

Psicológicas, 15(1), e-2355. doi: https://doi.org/10.22235/cp.v15i1.2355

Correspondência: Marina Zanella Delatorre, e-mail: marina_mzd@yahoo.com.br; Adriana Wagner, email:adrianaxwagner@gmail.com. Universidade Federal do Rio Grande do Sul. Rua Ramiro Barcelos, 2600 - Sala 126, Porto Alegre-RS, Brasil CEP: 90035-003.

Os relacionamentos íntimos e amorosos são considerados um importante aspecto da vida adulta (Rosado \& Wagner, 2015), sendo que a qualidade desses relacionamentos impacta a saúde individual e familiar (Robles, Slatcher, Trombello, \& McGinn, 2014; Stroud, Meyers, Wilson, \& Durbin, 2015) dos cônjuges. Atualmente, a forma como as relações amorosas são vivenciadas vem sofrendo transformações, motivando pesquisadores a investigarem novos arranjos conjugais, tais como os casais sem filhos por opção (Silva \& Frizzo, 2014), casais homossexuais (Lomando, Wagner, \& Gonçalves, 2011; Meletti \& Scorsolini-Comin, 2015), e casais de dupla carreira (Heckler \& Mosmann, 2016). Além de novos arranjos e configurações, a forma de compreender e vivenciar os relacionamentos também vem se modificando. Há maior valorização da satisfação e da liberdade individual (Borges, Magalhães, \& Féres-Carneiro, 2014), de forma que o vínculo conjugal fomente o crescimento pessoal de cada membro do casal. Esses novos arranjos, contudo, ainda coexistem com modelos e valores mais tradicionais de relacionamento (Costa \& Mosmann, 2015).

Além dos desafios trazidos por essas mudanças e pela coexistência de diferentes modelos, há uma dificuldade que se prolonga por décadas na literatura em definir o que é um relacionamento conjugal de qualidade (Fincham \& Bradbury, 1987; Heyman, Sayers, \& Bellack, 1994; Mosmann, Wagner, \& Féres-Carneiro, 2006). O fato de diferentes termos, como qualidade, satisfação, ajustamento e felicidade serem usados indiscriminadamente como sinônimos ou conceitos distintos, demonstra a dificuldade dos pesquisadores em chegar a um consenso sobre o tema (Delatorre \& Wagner, 2020; Rosado \& Wagner, 2015; Scorsolini-Comin \& Santos, 2010). Essa dificuldade se estende para além da escolha dos termos utilizados para a definição da própria natureza do construto. Para alguns autores, qualidade e satisfação 
conjugal são sinônimos, representando um construto unidimensional determinado pela avaliação global que os cônjuges fazem da relação (Fincham \& Bradbury, 1987; Norton, 1983). Para outros, trata-se de um construto complexo que envolve diferentes dimensões do relacionamento, para além da satisfação conjugal (Fletcher, Simpson, \& Thomas, 2000; Mosmann et al., 2006, Spanier \& Cole, 1976).

Diante desse cenário, alguns autores mapearam conceitos e teorias que explicam o construto de qualidade conjugal e as relações conjugais como um todo, buscando identificar suas contribuições à compreensão do construto (Karney \& Bradbury, 1995; Mosmann et al., 2006). Esses estudos revelam a complexidade envolvida no estudo do tema e apontam para a necessidade de modelos integrativos, que considerem o relacionamento de casal a partir de diferentes perspectivas (Mosmann et al., 2006). Nesse sentido, Karney e Bradbury (1995) desenvolveram o Vulnerability-Stress-Adaptation Model (Modelo de Vulnerabilidade, Estresse e Adaptação), combinando as contribuições mais importantes de cada uma das teorias revisadas.

O modelo busca não apenas explicar a qualidade conjugal, mas também a estabilidade e as mudanças no relacionamento ao longo do tempo, destacando três grupos de variáveis: eventos estressantes, vulnerabilidades individuais e processos adaptativos. De acordo com o modelo, os eventos estressantes que fazem parte do contexto do casal e as vulnerabilidades individuais dos cônjuges influenciam os processos adaptativos do casal. Esses processos representam a forma como o casal interage e responde um ao outro e aos fatores externos à relação. Os processos adaptativos, por sua vez, estabelecem uma associação recíproca com a qualidade conjugal. Essa definição é útil para delimitar as diferenças entre os componentes da qualidade conjugal e os processos adaptativos, evitando a sobreposição de construtos que tende a enviesar os estudos investigando a qualidade conjugal (Fincham \& Bradbury, 1987). Contudo, uma das limitações do modelo é considerar qualidade e satisfação conjugal como sinônimos, reduzindo a qualidade do relacionamento a uma avaliação subjetiva dos cônjuges. Apesar de evitar a sobreposição conceitual, esse tipo de definição dificulta a determinação do que de fato constitui a qualidade conjugal e a construção teórica do construto (Knapp \& Lott, 2010).

Nesse sentido, a Teoria Triangular do Amor (Sternberg, 1986) também propõe uma visão integrativa dos relacionamentos, embora o foco seja o amor e não os relacionamentos propriamente ditos. De acordo com a Sternberg, o amor é formado por três componentes: a intimidade, a paixão, e a decisão/compromisso. Esses componentes são derivados do investimento emocional, do envolvimento motivacional, e da decisão cognitiva, respectivamente. Cada componente tem um papel específico, desde o enamoramento e a formação do casal, passando pelo desenvolvimento do vínculo conjugal, até a manutenção da estabilidade do relacionamento. Assim, da mesma forma que o Vulnerability-StressAdaptation Model possibilita discriminar processos adaptativos e qualidade conjugal, a Teoria Triangular do Amor oferece um enquadre para compreender os componentes do construto.

No Brasil, alguns estudos já foram realizados tendo como base a teoria de Sternberg. Mônego e Teodoro (2011), por exemplo, encontraram correlações significativas entre os três componentes do amor e a satisfação conjugal. Os autores também investigaram os componentes do amor, os traços dos cinco grandes fatores de personalidade e o tipo de relacionamento como preditores da satisfação conjugal. Maiores níveis de intimidade, paixão e do traço de realização, assim como menor neuroticismo, foram preditores da satisfação com o relacionamento. Na mesma direção, os achados de Rizzon, Mosmann e Wagner (2013) revelaram correlações significativas entre os três componentes do amor e a satisfação conjugal em pessoas que estavam em um relacionamento há mais de 10 anos. No estudo conduzido por Rizzon et al. (2013), contudo, o componente compromisso foi preponderante em relação ao demais, o que pode ser explicado pela busca de estabilidade e segurança financeira na fase do ciclo vital em que os casais se encontravam.

Além dessas teorias propostas entre as décadas de 70 e 90, há iniciativas mais recentes de refinamento teórico e metodológico no campo da conjugalidade. Fowers e Owens (2010), por exemplo, propõem uma abordagem eudaimônica, na qual a satisfação conjugal emerge do grau de correspondência entre o relacionamento e os objetivos traçados para o relacionamento. Esses objetivos são classificados 
em duas dimensões, a agência e a comunhão. A agência diz respeito à relação entre os fins e os meios dos objetivos, podendo ser instrumental, em que um meio é empregado para alcançar determinado fim, ou constitutivo, em que meios e fins são inseparáveis, já que o meio de alcançar um determinado objetivo é um fim em si mesmo. Já a dimensão de comunhão diferencia os objetivos individuais dos compartilhados entre o casal. Nessa perspectiva, ter um bom emprego e o planejamento econômico familiar são objetivos individuais e compartilhados, respectivamente, ambos instrumentais. Exemplos de objetivos constitutivos são: assumir responsabilidades, um objetivo individual, e construir um relacionamento harmônico, um objetivo compartilhado. De acordo com essa perspectiva, os relacionamentos de maior qualidade apresentariam altos níveis de objetivos que fossem compartilhados e constitutivos.

Analisando essas teorias nota-se que, embora lancem luz sobre as variáveis que influenciam a qualidade do relacionamento, não fica claro o que cada uma delas considera como a qualidade conjugal propriamente dita. É possível perceber, contudo, que algumas teorias focalizam a percepção e a avaliação dos cônjuges, enquanto outras enfatizam comportamentos, ou combinam ambos os aspectos. Dentre as últimas, as teorias integrativas, como o Vulnerability-Stress-Adaptation Model, tendem a melhor abarcar a complexidade das relações conjugais (Mosmann et al., 2006). A aplicação de modelos complexos e integrativos, no entanto, muitas vezes resulta em um emaranhado de conceitos difíceis de distinguir entre si. Nesse sentido, é importante que os construtos que compõem o modelo sejam claros, bem definidos e operacionalizáveis.

Além da dificuldade em definir o que é qualidade conjugal, poucos estudos investigam as peculiaridades da percepção sobre os relacionamentos amorosos no contexto brasileiro. Embora alguns estudos investiguem a vivência de grupos específicos, como casais de dupla carreira (Heckler \& Mosmann, 2016), casais recasados (Silva, Trindade, \& Silva Junior, 2012) e diferenças relacionadas à conjugalidade em duas gerações (Coutinho \& Menandro, 2010), não foram encontrados estudos que investigassem as dimensões da qualidade do relacionamento conjugal e quais aspectos se relacionam a essa qualidade no contexto brasileiro. Conhecer a vivência dos casais e a sua perspectiva sobre o que é um relacionamento de qualidade pode contribuir com o desenvolvimento teórico do tema de forma coerente com o contexto local, além de fornecer ferramentas para o trabalho com casais. Dessa forma, o objetivo deste estudo foi propor dimensões relevantes ao construto de qualidade conjugal, a partir da perspectiva dos casais entrevistados, que foi compreendida com base na Teoria Triangular do Amor (Sternberg, 1986). Além disso, investigou-se como essas dimensões se relacionam a temas relativos ao indivíduo, ao contexto e aos processos adaptativos vivenciados pelos casais, com base no VulnerabilityStress-Adaptation Model (Karney \& Bradbury, 1995).

\section{Método}

\section{Participantes}

Oito casais participaram do estudo, sendo cinco heterossexuais e três homossexuais. Quanto à situação conjugal, cinco casais eram casados oficialmente e três moravam juntos. O tempo de união variou de 10 meses a 21 anos. Todos os casais residiam no estado do Rio Grande do Sul, Brasil, seis na região metropolitana e dois no interior do estado. A Tabela 1 detalha o perfil dos casais entrevistados. 
Tabela 1

Descrição dos casais entrevistados

\begin{tabular}{|c|c|c|c|c|c|c|c|c|c|}
\hline & & Idade & $\begin{array}{l}\text { Tempo de } \\
\text { relacionamento }\end{array}$ & $\begin{array}{l}\text { Situação } \\
\text { conjugal }\end{array}$ & Recasamento & Filhos & Escolaridade & Religião & Região \\
\hline \multirow[t]{2}{*}{$\begin{array}{l}\text { Casal } \\
1\end{array}$} & M & 31 & 9 anos e 1 mês & Coabitação & Não & Não & $\begin{array}{l}\text { Pós- } \\
\text { Graduação }\end{array}$ & Não & Metropolitana \\
\hline & $\mathrm{H}$ & 35 & & & Não & Não & Ens. Superior & & Metropolitana \\
\hline \multirow[t]{2}{*}{$\begin{array}{l}\text { Casal } \\
2\end{array}$} & M & 32 & 7 anos e 6 meses & Casados & Não & Não & $\begin{array}{l}\text { Pós- } \\
\text { Graduação }\end{array}$ & Não & Metropolitana \\
\hline & $\mathrm{H}$ & 34 & & & Não & Não & $\begin{array}{l}\text { Pós- } \\
\text { Graduação }\end{array}$ & Não & Metropolitana \\
\hline \multirow{2}{*}{$\begin{array}{l}\text { Casal } \\
3\end{array}$} & $\mathrm{H} 1$ & 36 & 10 meses & Coabitação & Não & Não & Ens. Médio & Não & Metropolitana \\
\hline & $\mathrm{H} 2$ & 28 & & & Não & Não & $\begin{array}{l}\text { Pós- } \\
\text { Graduação }\end{array}$ & Não & Metropolitana \\
\hline \multirow{2}{*}{$\begin{array}{l}\text { Casal } \\
4\end{array}$} & $\mathrm{H}$ & 37 & 5 anos e 2 meses & Casados & Sim & Sim & Ens. Superior & Adventista & Metropolitana \\
\hline & M & 41 & & & Sim & Sim & $\begin{array}{l}\text { Ens. } \\
\text { Fundamental }\end{array}$ & Adventista & Metropolitana \\
\hline \multirow[t]{2}{*}{$\begin{array}{l}\text { Casal } \\
5\end{array}$} & $\mathrm{H} 1$ & 26 & 3 anos e 4 meses & Coabitação & Não & Não & $\begin{array}{l}\text { Pós- } \\
\text { Graduação }\end{array}$ & Não & Metropolitana \\
\hline & $\mathrm{H} 2$ & 34 & & & Não & Não & Ens. Superior & Cristã & Metropolitana \\
\hline \multirow[t]{2}{*}{$\begin{array}{l}\text { Casal } \\
6\end{array}$} & M1 & 37 & 5 anos e 6 meses & Casadas & Não & Sim & $\begin{array}{l}\text { Pós- } \\
\text { Graduação }\end{array}$ & Cristã & Metropolitana \\
\hline & M2 & 39 & & & Não & Sim & $\begin{array}{l}\text { Pós- } \\
\text { Graduação }\end{array}$ & Católica & Metropolitana \\
\hline \multirow[t]{2}{*}{$\begin{array}{l}\text { Casal } \\
7\end{array}$} & M & 40 & 21 anos & Casados & Não & Sim & $\begin{array}{l}\text { Ens. } \\
\text { Fundamental }\end{array}$ & Católica & Interior \\
\hline & $\mathrm{H}$ & 47 & & & Não & Sim & $\begin{array}{l}\text { Ens. } \\
\text { Fundamental }\end{array}$ & Católica & Interior \\
\hline \multirow{2}{*}{$\begin{array}{l}\text { Casal } \\
8\end{array}$} & M & 43 & 20 anos e 10 & Casados & Não & Sim & Ens. Médio & Católica & Interior \\
\hline & $\mathrm{H}$ & 53 & & & Não & Sim & Ens. Médio & Católica & Interior \\
\hline
\end{tabular}

\section{Instrumentos e procedimentos de coleta dados}

Os participantes responderam a uma ficha de dados sociodemográficos e a uma entrevista semiestruturada, que foi realizada na presença de ambos os membros do casal. A entrevista investigava diversos aspectos do relacionamento, como a história do casal, as características que destacariam no cônjuge, a tomada de decisões, a comunicação, a demonstração de afeto, o manejo dos conflitos, e os aspectos considerados necessários para um relacionamento de boa qualidade. As questões relativas à tomada de decisões, à comunicação, às demonstrações de afeto e ao manejo dos conflitos foram realizadas em duas perspectivas. Primeiramente, era solicitado que o casal identificasse, em comum acordo, momentos felizes do relacionamento e, então, eram realizadas as questões relativas a este período. O mesmo procedimento era realizado em seguida considerando os momentos difíceis do relacionamento. As perguntas foram respondidas por ambos os membros de casal, sendo que quando apenas um dos cônjuges fornecia resposta era verificado se esta correspondia à percepção de ambos. Foram realizadas duas entrevistas piloto a fim de verificar se o roteiro elaborado seria compreendido pelos casais e se responderia aos objetivos da pesquisa. Além de responderem a entrevista, os casais que 
participaram desta etapa foram solicitados a opinar sobre a compreensão das questões e a abrangência da entrevista. Não houve modificações na entrevista após esse procedimento.

Os participantes foram encontrados a partir da rede de contatos das pesquisadoras. $\mathrm{O}$ critério de conveniência foi adotado a fim de abranger ao máximo as diferentes configurações e fases do ciclo vital conjugal/familiar na composição da amostra. As entrevistas foram realizadas em um encontro previamente agendado, após a assinatura do Termo de Consentimento Livre e Esclarecido, e tiveram cerca de uma hora de duração. Foram gravadas em áudio e transcritas na íntegra para análise. Os participantes foram informados de que não havia riscos previstos na participação no estudo, mas que, caso se sentissem desconfortáveis com alguma questão, poderiam optar por não responder ou interromper a participação na pesquisa. Além disso, foi assegurado de que seriam encaminhados a um serviço de atendimento psicológico gratuito caso necessário. Este estudo foi realizado de acordo com as normas previstas na Resolução 466/12 (Conselho Nacional de Saúde, 2012), que dispõe sobre a realização de pesquisas envolvendo seres humanos, e aprovado pelo Comitê de Ética do Instituto de Psicologia da Universidade Federal do Rio Grande do Sul.

\section{Análise dos dados}

O conteúdo obtido por meio das entrevistas foi submetido à análise temática (Braun \& Clarke, 2006). A identificação dos eixos temáticos foi realizada tomando como base o Vulnerability-StressAdaptation Model, descrito anteriormente. Dessa forma, os eixos temáticos foram definidos a priori, enquanto os temas foram determinados a partir do conteúdo das entrevistas. Esse modelo tem a vantagem de permitir a exploração de diversas variáveis agrupando os eventos estressantes, as vulnerabilidades individuais e os processos adaptativos. Os autores comparam essa abordagem à inclusão de itens em um questionário, já que as relações entre esses agrupamentos de variáveis que formam o construto teórico são mais importantes do que as intercorrelações entre as variáveis que compõem o modelo (Karney \& Bradbury, 1995). Neste estudo, a qualidade conjugal foi considerada a partir de uma perspectiva semelhante, a fim de identificar os temas que compõe o construto, em contraste com a abordagem adotada pelos autores do modelo, que consideram a qualidade conjugal como sinônimo de satisfação com o relacionamento. Por isso, a Teoria Triangular do Amor (Sternberg, 1986) foi utilizada como referência para compreender os temas componentes da qualidade conjugal.

A análise temática foi realizada por meio do software NVivo 11. Os temas identificados passaram pela concordância entre quatro juízes, mantendo-se aqueles que apresentaram um índice Kappa de concordância igual ou superior a 75\%. O índice Kappa foi calculado a partir da soma de respostas de um mesmo tema dividido pelo número de juízes e multiplicado por 100. As respostas que obtiveram $50 \%$ de concordância passaram pela avaliação de uma Professora Doutora com expertise na área e as demais foram desconsideradas na análise.

\section{Resultados}

A análise dos dados identificou cinco temas que compõem o eixo de qualidade do relacionamento conjugal. Outros 16 temas associados à qualidade conjugal foram identificados e organizados em três eixos temáticos: indivíduo, contexto e processos adaptativos, estabelecidos a partir do Vulnerability-Stress-Adaptation Model (Karney \& Bradbury, 1995). Uma representação gráfica dos eixos temáticos e temas é apresentada na Figura 1. 


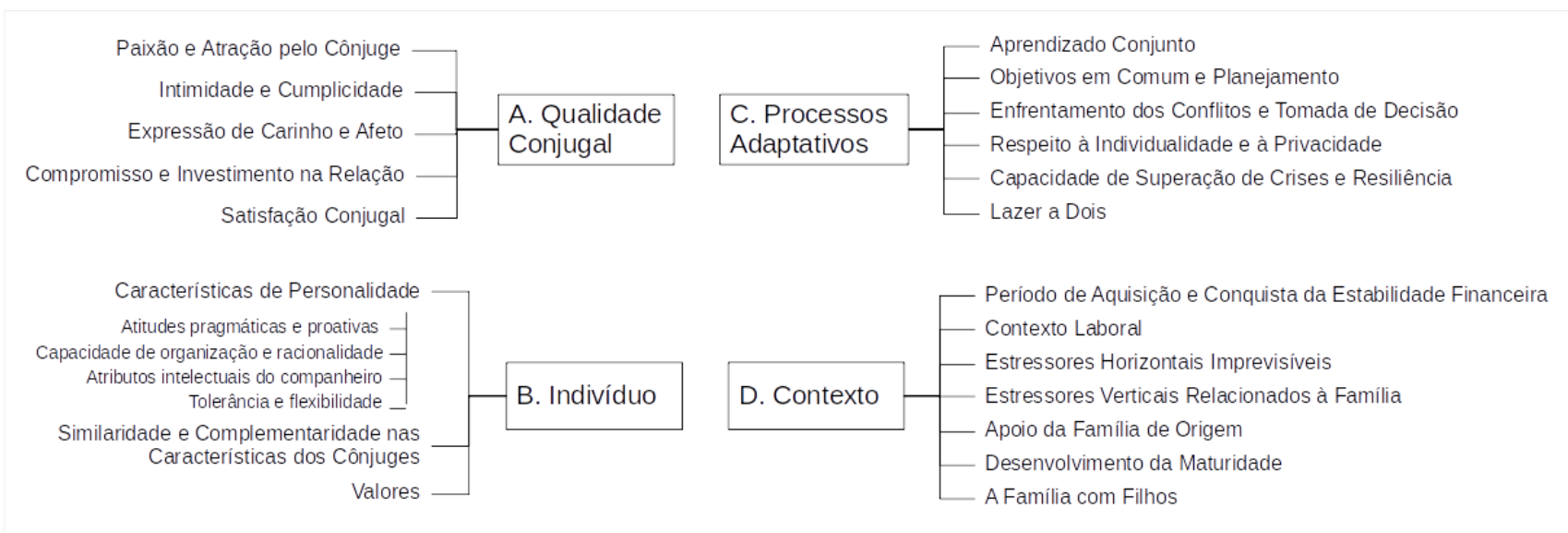

Figura 1. Eixos temáticos e temas identificados na análise.

\section{A. Eixo Qualidade Conjugal}

O eixo qualidade conjugal diz respeito à avaliação dos cônjuges sobre o seu relacionamento, que envolve o afeto, a intimidade, o compromisso e a sexualidade. Os conteúdos incluídos neste eixo foram obtidos principalmente da descrição de momentos felizes no relacionamento, em que os participantes abordaram a história do relacionamento, as características que destacariam no cônjuge, a demonstração de afeto e os aspectos considerados importantes para uma relação de boa qualidade. Esses aspectos conversam entre si na medida em que a atração e a sexualidade são elementos importantes no início do relacionamento, posteriormente dando espaço ao desenvolvimento do afeto e da intimidade, que impulsionam os parceiros a comprometerem-se e a investirem na relação. Estão expressos nos seguintes temas:

A.1. Paixão e atração pelo cônjuge. Os relatos sobre o relacionamento incluíram referências aos aspectos físicos e estéticos do cônjuge, além da paixão, da atração sexual e da vivência da sexualidade pelo casal: "Eu... sou apaixonado por ela ainda, sabe" (Homem, Casal 1); "Tem que ter tesão (...) a coisa de pele tem que funcionar" (Mulher 1, Casal 6); "bonita (...) continua bonita” (Homem, Casal 8). Embora tenham sido referidos como importantes no momento atual, esses aspectos foram apontados como mais relevantes no início do relacionamento.

A.2. Intimidade e cumplicidade. A intimidade apareceu como a experiência dos cônjuges de conhecerem profundamente um ao outro, desmistificando aspectos idealizados sobre o(a) companheiro(a) e favorecendo a comunicação não verbal, a partir da familiaridade com as formas de expressão do outro em diferentes situações: "por tá junto já há relativamente bastante tempo, né?... A gente já sente, a gente já sente... se o outro tá precisando disso ou daquilo, se tá querendo alguma coisa." (Homem, Casal 8). A partir da intimidade, é possível compartilhar experiências e sentimentos com o cônjuge, proporcionados pela abertura ao companheiro(a), além de experimentar sentimentos de proximidade, de cumplicidade, e de pertencimento à relação: "Cumplicidade... de saber que tu pode dividir com a pessoa não só as coisas boas, mas também as ruins." (Mulher, Casal 2); "sensação de pertencer a alguém, de fazer sentido pra alguém” (Mulher, Casal 4).

A.3. Expressão de carinho e afeto. A importância de demonstrar amor, carinho e afeto pelo(a) companheiro(a) também foi destacada nos relatos dos casais, abrangendo comportamentos como realizar atividades juntos, conversar e expressar carinho de forma física, trocando abraços, beijos e carícias: " $a$ gente tá junto, senta, toma chimarrão, os dois tão perto, os dois conversam, a gente se abraça, a gente se beija" (Homem 2, Casal 5). A expressão de carinho incluiu também demonstrar cuidado e preocupação com o outro e fazer pequenos agrados ao cônjuge: "Acho que a gente tem muito disso, 
dessas pequenas gentilezas, assim (...) cozinhar o que o outro gosta, comprar o que o outro gosta de comer, gosta de fazer" (Mulher 1, Casal 6).

A.4. Compromisso e investimento na relação. $O$ investimento no cotidiano a dois aparece com o papel de manutenção do relacionamento. Esse investimento requer compromisso com a relação, envolvendo apoio mútuo, companheirismo, esforço, dedicação e interesse por parte de ambos os cônjuges: "do casal estar empenhado em dar certo" (Homem, Casal 4); "foi bem importante pra nossa relação, assim, de caminhar juntos e tentar se apoiar nesses momentos" (Mulher, Casal 2); "essa convivência boa, esse ambiente familiar, e um compensa o outro, o companheirismo, a parceria, a necessidade de uma ajuda que precisa" (Mulher, Casal 8). Alguns relatos também indicam a importância de clareza sobre as expectativas a respeito do relacionamento: "eu tenho clareza do que eu quero, ela tem clareza do que ela quer. (...) A gente sabe, desde o começo a gente sabia que a gente queria alguém pra ficar junto, pra ter filho, pra ter familia, pra... acampar nas férias, sabe” (Mulher 1, Casal 6).

A.5. Satisfação conjugal. Este tema compreende os conteúdos relacionados à avaliação que os participantes fazem do relacionamento. Essas avaliações abrangem tanto momentos atuais como passados do casal, analisando o relacionamento como um todo e o impacto da relação na própria vida: "A gente tá assim no melhor momento de todos que a gente já viveu" (Mulher, Casal 1); "Eu digo assim, eu sem ela não seria, não seria a pessoa que sou, de jeito nenhum, né” (Homem, Casal 8).

$\mathrm{O}$ eixo qualidade conjugal demonstra como os temas que compõem a avaliação do relacionamento se articulam para integrar a percepção do casal sobre sua conjugalidade. Pode-se supor que o papel e a importância dos elementos da qualidade conjugal variam ao longo do tempo, embora todos sempre estejam presentes no relacionamento em alguma medida. A paixão, por exemplo, tende a ser importante como elemento motivador no início do relacionamento. Mesmo perdendo espaço para a construção da intimidade, que proporcionará coesão no relacionamento, a paixão continua presente por meio da sexualidade do casal. Da mesma forma, o compromisso e o investimento assumem maior destaque quando já há uma base relacional construída. O desenvolvimento da relação a partir da atração e do apaixonamento, porém, não seria possível na ausência de algum nível de investimento e disposição ao compromisso por parte dos membros do casal. Assim, uma visão multidimensional da qualidade conjugal considera todos os seus elementos de forma contextualizada ao momento em que o casal se encontra.

\section{B. Eixo Indivíduo}

O eixo indivíduo trata das características pessoais, valores, e particularidades trazidas ao relacionamento pelos membros do casal individualmente. Os conteúdos apresentados neste eixo são provenientes, principalmente, dos relatos sobre a história do casal e sobre as características que cada participante destacou no companheiro. As características pessoais são apontadas como um aspecto importante, tanto as de personalidade e valores do seu cônjuge que são admirados pelos entrevistados assim como atributos pessoais importantes para os relacionamentos conjugais em geral. Os casais reconhecem que tanto a similaridade como a complementaridade de características são importantes para o bom desenvolvimento do relacionamento.

B.1. Características de personalidade. Este tema retrata características específicas que chamam a atenção no companheiro(a), como o pragmatismo, a racionalidade e os aspectos intelectuais. Também estão incluídas características pessoais que os participantes consideram para os relacionamentos de maneira geral. Essas características estão organizadas nos quatro subtemas descritos a seguir:

B.1.1 Atitudes pragmáticas e proativas. No que diz respeito à proatividade e ao pragmatismo, destaca-se a importância do papel de tomar a iniciativa, batalhar, ter atitude e ser pragmático para o bom funcionamento do casal: "essa vontade, essa... inquietude de buscar, de tá sempre querendo coisas novas. Querendo ou não ele tá fazendo uma coisa, já quer duas e, pra frente, ele tá sempre muito pra frente." (Homem 2, Casal 5); "empenhada, batalhadora" (Homem, Casal 8).

B.1.2 Capacidade de organização e racionalidade. Características como calma, racionalidade, 
equilíbrio, capacidade de gestão e organização também foram destacadas pelos participantes: "é a capacidade de gestão, de organização (...) Eu olho pra ele e vejo como alguém importante, como alguém de credibilidade" (Homem 1, Casal 5).

B.1.3 Atributos intelectuais do companheiro. Os aspectos intelectuais do cônjuge, como inteligência e articulação, foram classificados pelos participantes como características atrativas e importantes no início e/ou na manutenção do interesse pelo(a) companheiro(a): "é uma parceria que me desafiava intelectualmente, assim. Eu acho que isso é bacana, ainda é hoje, assim” (Homem, Casal 2).

B.1.4. Tolerância e flexibilidade. Neste subtema, os participantes enfatizam a importância da tolerância, da paciência, da capacidade de agir de forma empática e relevar características do cônjuge ou atitudes e situações do dia a dia, agindo de maneira ponderada e flexível: "A capacidade de relevar as coisas que são, não são importantes, sabe, que não vale a pena" (Mulher 2, Casal 6); "O maior desafio do relacionamento é a tolerância, a paciência. Sem tolerância e paciência não tem casamento" (Mulher, Casal 8).

B.2. Similaridade e complementaridade nas características dos cônjuges. Os participantes referenciam a importância tanto da similaridade e de características em comum entre o casal como a existência de aspectos complementares entre os cônjuges. A similaridade se refere às semelhanças de pensamento e senso de humor, à afinidade, à harmonia e à existência de características em comum: "Sim. Gostava das mesmas coisas, gostava de sair..." (Mulher, Casal 7). Apesar da importância da afinidade, a existência de aspectos antagônicos e complementares em cada cônjuge também foi apontada como favorecedora do relacionamento: "realmente tem coisas bem antagônicas, que se complementam, acho que a gente se ajuda nesse sentido" (Homem 1, Casal 3). A racionalidade, por exemplo, aparece como complementar à proatividade, de forma que um dos cônjuges exerce um papel ponderado enquanto o outro assume a liderança das ações: 'eu sou aquele que 'não, mas calma...', 'veja bem...' E daí ela fala 'não, veja bem nada, vamos fazer as coisas"” (Homem, Casal 2).

B.3. Valores. Os valores, incluindo valores individuais, familiares e culturais, a fé e a forma de criação de cada um dos cônjuges também foram considerados importantes. Os participantes apontam o papel da semelhança ou da diferença dos valores, traços culturais e formas de criação de cada um no relacionamento: "se os valores estão de acordo, eu acho que o resto... dá certo" (Homem 1, Casal 3). A fé e a religião foram apontadas como tendo um papel importante no relacionamento por alguns casais. Os relatos expressam a força e a confiança obtidas por meio da fé, a participação do casal e/ou família em rituais religiosos e a importância dos valores ligados à religião para o casal: "E outra coisa é Deus, né, a gente tem que, a gente procura seguir uma religião, né, a religião católica. A gente procura passar isso para as crianças, a gente procura rezar junto em familia” (Homem, Casal 8).

O eixo indivíduo retrata como as características específicas trazidas ao relacionamento pelos cônjuges e a percepção que cada um tem das características do outro dão o tom aos processos que ocorrem entre o casal. Nesse sentido, são importantes tanto os valores pessoais como traços de personalidade de cada cônjuge. Os traços identificados, considerando os cinco grandes fatores de personalidade, foram: a realização (capacidade de gestão e organização), a abertura à experiência (buscar coisas novas) e a socialização (empatia), mas não a extroversão e o neuroticismo. Essas características desempenham um papel desde o início do relacionamento, uma vez que são levadas em conta na escolha conjugal. Além disso, as características em si e a forma como se combinam entre o casal constituem a base dos processos adaptativos, que serão discutidos a seguir.

\section{Eixo Processos Adaptativos}

O eixo processos adaptativos inclui os processos de interação, de tomada de decisões, e de construção do relacionamento, incluindo o estabelecimento de objetivos comuns e a definição sobre como o casal desfruta o tempo de que dispõem juntos, que possibilitam o crescimento e o estabelecimento de uma identidade conjugal. Os casais apontam a importância da confiança e do respeito entre os cônjuges para o desenvolvimento desses processos. Além disso, este eixo inclui a percepção de segurança sobre a manutenção do relacionamento, que se dá a partir da decisão de prosseguir o casamento 
mesmo em momentos de dúvidas e dificuldades. A maioria dos conteúdos neste eixo foi obtida a partir das perguntas sobre a tomada de decisões, a comunicação e o manejo dos conflitos, tanto em momentos felizes como difíceis do relacionamento.

C.1. Aprendizado conjunto. Os participantes fizeram diversas referências ao amadurecimento da relação, ao aprendizado obtido no enfrentamento de situações de crise pelo casal e da adaptação à vida a dois que ocorre como resultado da convivência e familiarização com o outro: "porque a gente se conheceu melhor, descobriu algumas qualidades e outros defeitos de cada um, e a gente também sempre se propõe a crescer juntos" (Homem 2, Casal 5). Este tema também expressa o entendimento dos participantes de que o relacionamento conjugal é uma construção constante, que ocorre a partir da vida cotidiana do casal: "essa batalha que tu vive aí, do dia a dia, acaba fortalecendo também o relacionamento, né?" (Homem, Casal 8).

C.2. Objetivos em comum e planejamento. A importância de ter planos e objetivos em comum também foi evidenciada pelos cônjuges. A existência de projetos conjuntos e a busca pelo crescimento de ambos ajudam a unir o casal: "Foco... o mesmo objetivo, o mesmo alvo... tem que querer a mesma coisa. Eu quero chegar lá...', 'ah, eu também', 'então vamos junto'.” (Mulher, Casal 4). Embora a maioria dos casais entrevistados tenha apontado a importância de planejamento de longo prazo, alguns participantes também alertam para a importância de viver o presente e focar no planejamento de curto prazo: "essa coisa de pensamento muito no futuro, planejamento de coisas, 'ah, quando isso for acontecer', acho isso nocivo (...) acaba... te tirando muito do presente, te colocando muito lá na frente" (Homem 1, Casal 3).

C.3. Enfrentamento dos conflitos e Tomada de decisão. A forma como os cônjuges interagem em momentos de enfrentamento de conflitos e tomada de decisão permeou todas as entrevistas. De maneira geral, os cônjuges se dividem entre aqueles que na maioria das vezes ignoram o assunto de conflito ou o guardam para si, tentando "não dar bola" e "ficar quieto", e aqueles que tendem a agir de maneira mais reativa, falando o que sentem e, algumas vezes, "explodindo": "Eu sou muito mais calmo, muito mais quieto (...) Então... quando ele chega e fala, estoura assim, normalmente, eu tento 'calma, calma' que tem momentos que a gente se altera um pouquinho. Mas acontece, depois passa, a gente conversa, a gente retoma" (Homem 2, Casal 3). Além disso, os casais relatam algumas dinâmicas recorrentes de resolução dos conflitos. Em muitos casos, primeiramente há uma discussão, seguida de um breve período de afastamento e, por fim, de um momento de diálogo e tentativa de resolução: " $A$ gente entra em atrito, tem a discussão, e... daí... tem um que pisa mais na bola do que o outro, normalmente. E dai a gente se afasta um pouco e depois a gente volta a conversar, assim" (Homem, Casal 2). Outra possibilidade é que um dos cônjuges perceba o incômodo do outro com alguma situação e busque conversar sobre o assunto. Por fim, alguns casais relatam que inicialmente há afastamento e tensão em relação ao tema de conflito, até que, após algum tempo, haja um alívio natural da tensão e os dois voltem a interagir: "Então, às vezes, a gente não... em função de alguma briga, não se conversa, né? (...) ao deitar um vira pra um lado, outro pro outro (riso), e dorme. Aí passa um dia, passa dois, até que a necessidade do dia a dia faz com que você volte a conversar" (Mulher, Casal 8). Os relatos dos casais também demonstram que, frequentemente, um dos cônjuges possui mais facilidade em abordar o outro e iniciar o diálogo na tentativa de negociar ou resolver o conflito. No que diz respeito à tomada de decisão, os participantes relatam que conversam sobre as diferentes possibilidades até chegar a um consenso: "ver vários lugares assim, um cita um lugar, outro cita outro, dai a gente olha o que tem em um, o que tem no outro e em conjunto a gente... [toma a decisão]" (Mulher, Casal 7).

C.4. Respeito à individualidade e à privacidade. Os participantes valorizaram a preservação do espaço individual de cada cônjuge no relacionamento, respeitando o espaço do outro e mantendo o próprio espaço, mantendo certo grau de independência e o investimento em outros aspectos que não apenas a vida a dois: "de respeitar o espaço do outro. De tu cultivar o teu espaço, mas também deixar o outro ter o espaço dele" (Homem 2, Casal 3). Entretanto, também há relatos que indicam um apagamento da individualidade em função do casamento e/ou da família: "eu vou esquecer o meu eu e vou virar a página, e vamos achar o lado melhor do outro porque eles [os filhos] precisam do pai 
presente, precisam de eu presente (...) o 'eu' acaba meio que sumindo da vida da pessoa, né" (Mulher, Casal 8). Por fim, o tema também reúne conteúdos que remetem à falta de privacidade, em que a preservação da individualidade fica prejudicada por questões de espaço físico ou da presença constante do cônjuge: "esse espaço de ficar sozinha, que é uma coisa que eu sempre valorizei muito, porque eu morei muito tempo sozinha, também, era meio dificil" (Mulher, Casal 2).

C.5. Capacidade de superação de crises e resiliência. Este tema abrange os conteúdos referentes à percepção de solidez, estabilidade e segurança do relacionamento que resultam dos momentos de superação de crises: "[a relação] se tornou mais sólida do que a gente imaginava. Porque é isso, quando a gente mais precisou a gente sabia que podia contar com esse fator de estabilidade" (Homem, Casal 2). Nos relatos incluídos neste tema, os participantes se referem ao casamento como uma base segura e ressaltam a importância da decisão de seguir no relacionamento nos momentos difíceis que enfrentam: "eu acho que ainda num todo, é bom estar casado, é bom ter uma família. É bom ter essa base, essa segurança... Ter pra onde voltar, tu entende?" (Mulher, Casal 8).

C.6. Lazer a dois. Os momentos de lazer e descontração aparecem nas falas dos casais como importantes para a manutenção da saúde do relacionamento. O lazer inclui momentos em que possam estar à vontade um com o outro e investir o tempo em atividades tais como ver filmes, cozinhar, dançar, acampar e viajar: "a gente gosta de cozinhar, de viajar, a gente gosta de acampar" (Mulher 1, Casal 6); "Então chega o final de semana, a gente se arruma e... e sai para jantar fora. Tipo assim, aquilo ali é um alivio da semana..., faz bem pra nós" (Mulher, Casal 7); "ficar junto mesmo, relaxado, sem se preocupar com compromissos e problemas.... Procurando se divertir mesmo... brincar" (Homem, Casal 1).

O eixo processos adaptativos se apresenta como um elemento central na conjugalidade. Por meio desses processos, os cônjuges estabelecem sua dinâmica de relacionamento, acomodando aspectos individuais por meio do enfrentamento dos conflitos e construindo a conjugalidade a partir do aprendizado conjunto. Esse aprendizado resulta da convivência e da capacidade do casal em articular seus recursos para enfrentar momentos de crise, sejam essas crises associadas ou não ao relacionamento. Nesse sentido, é fundamental que haja objetivos em comum a serem alcançados, para que o casal construa seu caminho na mesma direção. O investimento no lazer a dois e o respeito à individualidade contribuem para manter a saúde conjugal, evitando sobrecarregar o relacionamento. A confiança e o respeito mútuo podem ser entendidos como condições necessárias para que esses processos se estabeleçam de forma adaptativa.

\section{Eixo Contexto}

O eixo contexto abrange os fatores externos ao relacionamento, incluindo elementos pertencentes ao núcleo familiar ou à família estendida. Esses aspectos apareceram nas questões sobre a história do casal e sobre momentos específicos do relacionamento, tanto felizes como difíceis. Os casais apontam o papel do contexto como disparador de estresse no relacionamento, mas também como fonte de apoio e impulsionador de mudanças.

D.1. Período de aquisição e conquista da estabilidade financeira. A estabilidade financeira, incluindo a renda e a administração do dinheiro do casal ou da família, e de questões materiais envolvendo principalmente a necessidade de moradia própria, foi apontada como fator importante pelos casais: "Então até construir a nossa casa, a questão financeira não permite a gente sair pra um aluguel, então eu fico presa ali" (Mulher, Casal 4); "É a questão de não ter o nosso próprio espaço. (... ) a gente já percebe que isso gera uma certa dificuldade, que a gente não consegue avançar, não consegue... impor ou organizar as coisas da nossa forma" (Homem 2, Casal 5). Os relatos incluídos neste tema tratam também do manejo das finanças pelos casais e do impacto positivo da estabilidade ou do aumento de renda no dia a dia dos cônjuges: "esse último [ano] tem sido bem bom pra mim porque... a gente tá com uma estabilidade financeira..." (Mulher, Casal 1).

D.2. Contexto Laboral. O contexto laboral parece interagir com o relacionamento de diversas formas. O excesso de trabalho, a dificuldade de dar conta das demandas da vida profissional, a 
insatisfação com o trabalho, e a preocupação com o desemprego são apontadas como formas de influência deste tema no relacionamento: "não tava conseguindo dar conta do meu trabalho, e eu sentia que deixava a desejar também no relacionamento" (Homem, Casal 2). A preocupação com o trabalho também aparece como relacionada à necessidade de prover o sustento da família: "se tu tem problema lá no teu trabalho isso acaba te dando um certo receio de você perder aquilo e não ter como suprir, sustentar a família. Então quando tem um problema lá no trabalho, ele passa a te prejudicar e, queira ou não, ele vem pra dentro de casa" (Homem, Casal 8).

D.3. Estressores horizontais imprevisíveis. Eventos inesperados apareceram como estressores em diversos momentos da trajetória conjugal. Esses estressores consistem em falecimento ou separação de familiares, crise financeira, momentos de transição e planos que não puderam ser concretizados conforme o esperado por motivos alheios ao casal: "essa mudança, porque envolve fechar apartamento, fechar as coisas aqui, tá nos deixando bastante ansiosos" (Homem, Casal 2). A crise financeira e o desemprego aparecem com destaque entre esses eventos: "começou a nossa crise financeira e a gente vendeu a casa, foi pagar aluguel com dois filhos pequenos, ai foi bem dificil" (Mulher, Casal 7).

D.4. Estressores verticais relacionados à família. Este tema reúne os conteúdos relacionados aos problemas na família de origem de um ou ambos os cônjuges. Os participantes relatam o impacto dos eventos que acontecem nas famílias sobre o casal, a influência de familiares que coabitam ou convivem cotidianamente com os cônjuges, e a existência de conflitos familiares: "E as famílias, né, acho que as famílias tão sempre permeando os problemas" (Homem, Casal 1); "a mãe dele não me aceita (...) a gente não se dá bem, então ela faz de tudo pra afastar as crianças de mim”" (Mulher, Casal 4).

D.5. Apoio da família de origem. O apoio recebido pelos cônjuges de fontes externas, especialmente da família, foi destacado por alguns participantes: "A família também... a família tá sempre ali" (Mulher, Casal 1). Esse apoio ocorre de diversas formas, como auxílio material, ajuda na execução de tarefas do dia a dia e apoio emocional: "eu saía trabalhar, ela que cuidava, ou quando estavam doentes eu pedia ajuda pra mãe. Ou minha irmã também sempre vinha socorrer" (Mulher, Entrevista 7).

D.6. Desenvolvimento da maturidade. Os participantes também referiram que a maturidade dos cônjuges, que aparece associada à idade, é um fator importante para o relacionamento: "Eu considero que eu sou uma pessoa muito melhor hoje do que eu era lá atrás, a maturidade, as duas, a gente se conheceu depois dos trinta" (Mulher 2, Casal 6). A maturidade, segundo os participantes, proporciona flexibilidade e estabilidade emocional aos membros do casal: "eu me percebo muito mais maduro (...) afetivamente, emocionalmente assim, muito mais estável, porque... antes eu era muito mais inseguro" (Homem 2, Casal 5).

D.7. A família com filhos. A chegada dos filhos, de maneira geral, é apontada como um momento de felicidade e realização do sonho de constituição de família: "a gente planejou... e aquela chegada com saúde, exatamente, até do jeito que a gente pensava eles vieram... as características assim, então foi... nossa, foi muita alegria" (Mulher, Casal 7). Também se destaca a necessidade de adaptação frente as demandas e tarefas inerentes à criação dos filhos. Apesar disso, a presença dos filhos é entendida como geradora de gratificação na medida em que os pais percebem o sucesso da transmissão de seus próprios valores aos filhos e os consideram como fortalecedores do vínculo conjugal: "Depois quando eles começam a retribuir tudo o que tu passa, eu acho que é um momento muito bacana (...) a gente conseguiu passar os valores pra eles e eles conseguem mantê-los” (Mulher, Casal 8). Para os cônjuges recasados, também aparece a importância de haver um bom relacionamento entre os filhos e o novo cônjuge para o sucesso do relacionamento atual: "Sempre tratou muito bem meus filhos, sempre teve carinho por eles, eles sempre perceberam isso (...) isso foi muito, muito, muito importante pra mim" (Mulher, Casal 4).

O eixo contexto abrange o entorno do casal, principalmente no que diz respeito aos fatores financeiros, laborais e ao ciclo vital familiar. Esses fatores interagem entre si, já que o período de aquisição financeira depende do contexto laboral e, muitas vezes, coincide com o desenvolvimento da 
maturidade e com a chegada dos filhos. Nesses momentos, o apoio da família de origem é fundamental para ajudar o casal a atender às demandas dessa fase e aos eventos estressores imprevisíveis, sem que haja uma sobrecarga excessiva no relacionamento. A família, no entanto, pode também se apresentar como um estressor, seja pela intrusão da família de origem na família nuclear ou pelas questões familiares que reverberam no relacionamento do casal.

\section{Discussão}

Este estudo buscou aclarar o construto de qualidade conjugal, compreendido com base na Teoria Triangular do Amor (Sternberg, 1986), propondo dimensões que elucidem a intersecção de temas relativos ao indivíduo, ao contexto e os processos adaptativos, na perpectiva de casais conforme o Vulnerability-Stress-Adaptation Model (Karkey \& Bradbury, 1995). No que diz respeito à qualidade conjugal, alguns dos temas identificados como componentes do construto neste estudo são correspondentes à Teoria Triangular do Amor, composta pela decisão/compromisso, intimidade e paixão. Essa teoria oferece uma abordagem abrangente dos relacionamentos românticos, incluindo aspectos emocionais, cognitivos e motivacionais. O componente decisão/compromisso é similar ao tema Compromisso e Investimento na Relação identificado neste estudo na medida em que representa o compromisso cognitivo com o relacionamento e a decisão e clareza sobre o que esperar da relação (Sternberg, 1986). Entretanto, esse componente, conforme identificado neste estudo, também inclui um aspecto comportamental, referente ao empenho investido no relacionamento e na prestação de apoio ao cônjuge para que a relação a dois se desenvolva.

Quanto ao aspecto emocional, os relatos dos participantes sobre a Intimidade e Cumplicidade foram similares à conceituação de Sternberg (1986) sobre a intimidade, enfatizando a proximidade entre o casal e uma familiarização que facilita a comunicação não verbal. Neste estudo, outro aspecto emocional também foi identificado como pertencente à qualidade conjugal: a Expressão de Carinho e Afeto. Esse tema representa pequenas ações cotidianas em que os parceiros demonstram afeto, cuidado e preocupação um com o outro. Essas demonstrações são especialmente importantes no decorrer do relacionamento, pois podem compensar o declínio da paixão e da sexualidade que costuma ocorrer ao longo do tempo nas relações conjugais (Rizzon et al., 2013; Sternberg, 1986).

O tema Paixão e Atração pelo Cônjuge, por sua vez, recebeu menos destaque nas entrevistas. Isso pode ser explicado tanto pela dificuldade em tratar abertamente deste tema com uma pessoa externa ao relacionamento, de forma a proteger a intimidade do casal, como pelo fato desse aspecto se tornar mais secundário no relacionamento com o passar do tempo, de acordo com a literatura (Rizzon et al., 2013; Sternberg, 1986) e com os próprios entrevistados. Já o tema Satisfação Conjugal é um aspecto amplamente estudado na literatura sobre conjugalidade, sendo consenso como componente da qualidade do relacionamento (Karney \& Bradbury, 1995; Mosmann et al., 2006).

O eixo processos adaptativos representa um conjunto de variáveis largamente investigado na literatura, especialmente pelas teorias comportamentais, no que diz respeito à comunicação e ao enfrentamento de conflitos (Baucom et al., 2015; Gottman, Driver, \& Tabares, 2015). Contudo, outras variáveis incluídas nesses processos são importantes e vêm ganhando espaço na literatura recente. $\mathrm{O}$ lazer e o tempo que o casal desfruta juntos, por exemplo, têm sido apontados na literatura nacional como fatores relacionado à qualidade do relacionamento e aos conflitos conjugais (Costa \& Mosmann, 2015; Heckler \& Mosmann, 2016; Mosmann \& Falcke, 2011). Além disso, um modelo teórico recente das relações conjugais propõe que os objetivos dos cônjuges, especialmente os objetivos compartilhados, têm um papel importante não apenas na qualidade do relacionamento, mas também no crescimento do casal, particularmente quando o enriquecimento da relação é um fim em si mesmo (Fowers \& Owenz, 2010). Os temas Objetivos em Comum e Planejamento e Aprendizado Conjunto interagem entre si de forma coerente com esse modelo, na medida em que, no relato dos participantes, o aprendizado conjunto se associa à forma como o casal se organiza para alcançar objetivos comuns, à convivência e ao 
enfrentamento de adversidades. Pode-se pensar que, por meio desses processos, também se constrói uma identidade conjugal a partir das trocas entre os parceiros, da construção de uma história e de significados comuns, conforme já descrito na literatura nacional (Féres-Carneiro, 1998; Féres-Carneiro \& Diniz-Neto, 2010). Nesse sentido, a partir desse eixo é possível integrar não só os achados deste estudo em relação ao Vulnerability-Stress-Adaptation Model, mas também achados da literatura nacional e elementos de modelos recentes que buscam explicar os relacionamentos de casal.

No que se refere ao indivíduo, a importância de preservar a individualidade é marcada na fala dos casais, especialmente os mais jovens. Essa é uma tendência apontada na literatura nacional já há duas décadas (Féres-Carneiro, 1998). Apesar disso, a individualidade não aparece como incompatível com a construção de uma realidade conjugal, mas sim como um valor a ser preservado pelos cônjuges, capaz de fortalecer o relacionamento, na medida em que esses aspectos individuais continuam despertando novos interesses ao longo do tempo. Assim, para alguns casais, parece já haver mais facilidade em conciliar aspectos da individualidade e da conjugalidade que antes pareciam conflitantes.

As características individuais trazidas ao relacionamento pelos cônjuges e o contexto em que o casal está inserido, incluindo seu entorno, estressores e recursos disponíveis, parecem interagir com os processos adaptativos e com a qualidade do relacionamento. As características individuais podem assumir um papel já na escolha conjugal (Féres-Carneiro, 1987; 1997), além de balizar os processos que ocorrem entre o casal. Casais cujos membros têm valores diferentes, por exemplo, podem ter mais conflitos relacionados a esse tema (Curtis \& Ellison, 2002; Mahoney, 2005). Além disso, a maneira como o casal resolverá esses conflitos pode ser favorecida ou não pelas características do indivíduo. Pode-se pensar que traços de personalidade como a socialização e a abertura facilitem a comunicação e encaminhamento dos conflitos ao passo que características relacionadas à inflexibilidade e instabilidade emocional dificultem esses processos (Vater \& Schröder-Abé, 2015).

A similaridade entre os parceiros e a existência de valores em comum também parece ter um papel relevante na definição dos objetivos do casal e na administração do tempo de que dispõem juntos. De fato, a percepção de similaridade de personalidade entre os cônjuges é um fator relacionado à satisfação e ao sucesso no relacionamento (Barelds \& Barelds-Dijkstra, 2007). Já as diferenças, entendidas como complementares, têm um papel importante na definição de certos papéis assumidos pelos parceiros. Características complementares tendem a oferecer um conjunto mais diversificado de habilidades para realizar as tarefas que precisam ser cumpridas pelo casal. A literatura documenta que a complementaridade é especialmente importante para casais de meia-idade, uma vez que as demandas dessa fase são menos orientadas à construção de uma realidade compartilhada e da intimidade entre o casal, e mais voltadas ao cumprimento de tarefas como a criação dos filhos e o sustento familiar (Bohns et al., 2013; Shiota \& Levenson, 2007).

Essas tarefas também aparecem como um fator relevante para a conjugalidade, agrupadas no eixo Contexto. Neste eixo, as questões financeiras e materiais tiveram um papel importante, estando relacionadas inclusive à satisfação conjugal, conforme aponta também a literatura internacional, especialmente em casais de menor nível socioeconômico (Maisel \& Karney, 2012). Aliado às questões econômicas, o trabalho também impacta na conjugalidade, especialmente em casais de dupla carreira (Heckler \& Mosmann, 2016). Esse impacto, no entanto, pode ser mitigado pela maneira como os parceiros lidam com as demandas do trabalho. Por exemplo, há evidências de que a capacidade de otimizar recursos como tempo, dinheiro e energia contribui para melhorar o funcionamento individual e conjugal em diversas áreas (Unger, Sonnentag, Niessen, \& Kuonath, 2015).

Assim, fatores associados ao contexto podem reverberar nos processos adaptativos tanto de maneira negativa como positiva. Dificuldades financeiras e eventos inesperados podem aumentar a tensão entre o casal e dificultar o planejamento e realização de objetivos, por exemplo. O enfrentamento dessas situações, no entanto, pode trazer crescimento e aprendizado ao relacionamento, muitas vezes contando com o apoio do próprio contexto, sob forma de suporte familiar e social.

Isso pode explicar o fato dos casais muitas vezes se referirem aos eventos inesperados como promotores do aprendizado e crescimento do casal, ainda que esses estressores exijam investimento de 
tempo e energia. Os estressores horizontais já estão descritos na literatura como fatores de contexto que são parte do ciclo vital familiar, responsáveis pelo aumento da tensão familiar em eventos inesperados ou pontos de transição (McGoldrick \& Shibusawa, 2016). A existência de apoio externo nesses momentos, especialmente por parte da família, também foi apontada como relevante nesse enfrentamento. Embora os estressores horizontais sejam frequentemente associados à diminuição da capacidade de interações construtivas entre o casal (Helms et al., 2014; Ledermann, Bodenmann, Rudaz, \& Bradbury, 2010; Maisel \& Karney, 2012), é possível que esse efeito seja atenuado e que essas situações sejam utilizadas a favor do desenvolvimento conjugal. Esse entendimento é fundamental para o trabalho com casais, pois indica que a promoção da capacidade de enfrentamento do estresse pelos parceiros e o fortalecimento de redes de apoio ao casal podem ser ferramentas complementares ao treinamento de habilidades de interação para melhorar a qualidade do relacionamento.

Já os filhos, para os casais que os têm, foram entendidos como a concretização de um projeto de vida que inicia com o nascimento dos filhos e culmina na transmissão dos valores do casal para a próxima geração, o que também aparece em registros anteriores na literatura nacional (Costa \& Mosmann, 2015). O momento da chegada dos filhos é marcado pela felicidade, mas também pela necessidade de atender a novas demandas, muitas vezes necessitando do apoio da família ampliada. Nesse sentido, os filhos interagem com outros fatores contextuais, seja pela maior necessidade de aproximação das famílias de origem e de apoio para o casal durante um período de adaptação e intensas demandas, pela necessidade de reorganização financeira, ou pela motivação de buscar melhores condições materiais para prover educação de qualidade e conforto aos filhos. Dessa forma, assim como os demais fatores contextuais, os filhos podem representar tanto uma fonte de estresse e desgaste do relacionamento conjugal, como impulsionar a melhoria do ambiente familiar e das condições de vida na família. Fatores como a percepção de alta autoeficácia parental, a existência de uma aliança de coparentalidade (Kwan, Kwok, \& Ling, 2015) e o apoio externo são importantes para que o casal parental mantenha a boa qualidade conjugal.

Esses resultados, tomados como um todo, estão de acordo com as relações propostas pelo Vulnerability-Stress-Adaptation Model, que prevê que casais que contam com processos adaptativos efetivos, enfrentam contextos pouco estressantes e têm características individuais favoráveis devem apresentar relacionamentos de maior qualidade (Karney \& Bradbury, 1995). Além disso, esses resultados estão de acordo com a literatura nacional prévia (Costa \& Mosmann, 2015; Heckler \& Mosmann, 2016; Scheeren, Vieira, Goulart, \& Wagner, 2014; Wagner, Mosmann, Scheeren, \& Levandowski, 2019), indicando a utilidade do modelo para integrar os achados desses estudos em um conjunto coerente. Embora comparar casais com diferentes níveis de qualidade conjugal esteja além do escopo deste estudo, as falas dos participantes demonstram o papel central dos processos adaptativos na relação entre os diversos temas identificados.

Os Processos Adaptativos parecem funcionar como intermediários entre os eixos Contexto e Indivíduo e o eixo Qualidade Conjugal, na medida em que as características dos cônjuges e do contexto em que estão inseridos tendem a reverberar na qualidade conjugal a partir dos processos de interação entre o casal. Assim, pode-se pensar que os aspectos individuais e do contexto reverberam nos processos relacionais que ocorrem entre o casal por meio do enfrentamento dos conflitos, e do estabelecimento de objetivos comuns entre o casal, por exemplo. Esses processos, por sua vez, reverberam na qualidade do relacionamento. Por exemplo, a existência de confiança e a capacidade de abordar o outro e dialogar podem favorecer tanto a expressão de afeto como a intimidade, ao passo que essa última pode facilitar a expressão não-verbal. Da mesma forma, os processos de planejamento e objetivos comuns agregam uma perspectiva de longo prazo ao relacionamento, que podem contribuir para o investimento e a sensação de compromisso com o relacionamento. Essa relação é apoiada por achados de estudos nacionais e internacionais (Gana, Saada, Broc, Kolec, \& Cazauvieilh, 2016; Hardy, Soloski, Ratcliffe, Anderson, \& Willoughby, 2015; Scheeren et al., 2014).

A relação entre indivíduo, contexto e processos adaptativos pode ser pensada em termos das tarefas as quais o casal precisa encaminhar ao longo do relacionamento. Em termos gerais, podem-se 
considerar como tarefas do casal a acomodação das características e anseios individuais de cada membro da díade em uma realidade conjugal compartilhada (Féres-Carneiro, 1998) e o encaminhamento de demandas apresentadas pelo contexto, como o surgimento de instabilidade financeira, trocas de emprego e moradia e o nascimento dos filhos. A forma como o casal lida com essas tarefas pode ser entendida, de acordo com os critérios adotados neste estudo, como processos adaptativos. Nesse sentido, pode-se avaliar alguns aspectos da relação conjugal para verificar como se dão esses processos e sua reverberação na qualidade do relacionamento. Esses aspectos podem incluir, por exemplo: a forma como o casal se comunica para acomodar suas características e como resolve as divergências que surgem nesse processo; a forma como conciliam os objetivos de vida de cada cônjuge em um planejamento conjunto; e a administração das tarefas frente ao tempo livre que possuem, de forma a atender essas demandas mas também reservar espaço para o lazer, que aproxima o casal e contribui para a construção e manutenção da intimidade.

A partir dessa perspectiva, entende-se que a forma como o casal encaminha essas questões vai delineando a qualidade conjugal em suas diferentes dimensões ao longo do relacionamento. Espera-se, por exemplo, que a necessidade de enfrentar juntos tais demandas gerem disposição para investir e se comprometer com o relacionamento. $\mathrm{O}$ exercício desses processos adaptativos também pode servir para aproximar o casal, gerando sensação de pertencimento, criando uma realidade compartilhada e alimentando a intimidade entre os cônjuges. Essa intimidade, junto à capacidade de comunicação, deve permitir a expressão do carinho e da sexualidade entre o casal.

Assim, intervir nos processos adaptativos parece ser uma forma efetiva de promover a qualidade conjugal. Esses processos são mais facilmente modificáveis pois são constituídos de habilidades que podem ser treinadas e ensinadas aos casais (Halford, Markman, Kline, \& Stanley, 2003). Por isso, são uma via de trabalho importante tanto na clínica como em intervenções de promoção da saúde conjugal.

\section{Considerações Finais}

Este estudo ratifica a importância das características individuais, do contexto e dos processos adaptativos ao se considerar a qualidade do relacionamento. Os resultados demonstraram como um modelo teórico proposto no contexto internacional se apresenta na percepção dos casais investigados neste estudo. Os resultados obtidos são coerentes com o modelo, indicando quais aspectos se destacam no contexto local e como achados de estudos nacionais podem ser integrados à perspectiva proposta pelo modelo teórico. Assim, uma das principais contribuições deste estudo foi a proposição de dimensões relevantes para a conceituação da qualidade conjugal por meio da compreensão dos dados dos casais a partir do Vulnerability Stress Adaptation Model.

Em termos de implicações práticas, o fato dos processos adaptativos assumirem um papel central indica que é importante investir nesses aspectos no trabalho com casais, especialmente tendo em vista que os processos adaptativos são mais facilmente modificáveis quando comparados ao contexto e aos aspectos individuais. Além disso, há indicativos de que aspectos contextuais que se apresentam como estressores aos parceiros podem ser utilizados de forma construtiva, favorecendo os processos adaptativos e, assim, aumentando a qualidade conjugal. É possível que a educação sobre estratégias para lidar com o estresse seja uma via de promoção da saúde não apenas individual mas também conjugal, de forma que a mudança de um dos parceiros reverbere no subsistema conjugal.

Este estudo possui algumas limitações. Primeiramente, o tamanho limitado da amostra não permitiu abranger toda a diversidade de fases do ciclo vital e configurações conjugais e familiares possíveis. O perfil da amostra foi heterogêneo em termos de situação conjugal, tempo de relacionamento e orientação sexual. Entretanto, neste estudo optou-se por uma análise de dados horizontal, sem explorar as especificidades da amostra, uma vez que o objetivo foi identificar temas relevantes para a qualidade conjugal de maneira geral. Assim, buscou-se diversificar ao máximo as características dos casais entrevistados, sendo que foi possível identificar muitos processos comuns que se sobrepõem às 
diferenças. Além disso, o tema do estudo envolve valores e desejabilidade social, o que pode ter influenciado de alguma forma os relados obtidos nas entrevistas. Da mesma forma, alguns temas como a sexualidade puderam ser explorados apenas de forma superficial. Os casais entrevistados na fase piloto apontaram que, ainda que este seja um tema relevante, os cônjuges não se sentem à vontade para tratar abertamente da sexualidade em um contexto de pesquisa, com alguém externo ao relacionamento com quem há pouca intimidade.

A partir dos resultados obtidos, é importante que estudos futuros continuem analisando as relações propostas pelo modelo investigado neste estudo. Novos estudos poderiam investigar como os aspectos discutidos se manifestam em amostras com características diferentes dos casais entrevistados neste estudo e em outras regiões do Brasil. Além disso, estudos quantitativos investigando se esses achados podem ser generalizados para populações mais amplas são necessários para aprofundar o conhecimento sobre as relações conjugais no contexto nacional.

\section{Referências}

Barelds, D. P. H., \& Barelds-Dijkstra, P. (2007). Love at first sight or friends first? Ties among partner personality trait similarity, relationship onset, relationship quality, and love. Journal of Social and Personal Relationships, 24(4), 479-496. doi: 10.1177/0265407507079235

Baucom, B. R., Dickenson, J. A., Atkins, D. C., Baucom, D. H., Fischer, M. S., Weusthoff, S., Hahlweg, K., \& Zimmerman, T. (2015). The interpersonal process model of demand/withdraw behavior. Journal of Family Psychology, 29(1), 80-90. doi: 10.1037/fam0000044

Bohns, V. K., Lucas, G. M., Molden, D. C., Finkel, E. J., Coolsen, M. K., Kumashiro, M., Rusbult, C. E., \& Higgins, E. T. (2013). Opposites fit: Regulatory focus complementarity and relationship well-being. Social Cognition, 31(1), 1-14. doi: 10.1521/soco.2013.31.1.1

Borges, C. C., Magalhães, A. S., \& Féres-Carneiro, T. (2014). Liberdade e desejo de constituir família: Percepções de jovens adultos. Arquivos Brasileiros de Psicologia, 66(3), 89-103.

Braun, V., \& Clarke, V. (2006). Using thematic analysis in psychology. Qualitative Research in Psychology, 3(2), 77-101. doi: 10.1191/1478088706qp063oa

Conselho Nacional de Saúde (2012). Resolução nº 466/2012 - Dispõe sobre pesquisa envolvendo seres humanos. Brasil: Ministério da Saúde, Brasília, DF.

Costa, C. B., \& Mosmann, C. (2015). Relacionamentos conjugais na atualidade: Percepções de indivíduos em casamentos de longa duração. Revista da SPAGESP, 16(2), 16-31.

Coutinho, S. M. S., \& Menandro, P. R. M. (2010). Relações conjugais e familiares na perspectiva de mulheres de duas gerações: "Que seja terno enquanto dure”. Psicologia Clínica, 22(2), 83-106. doi: 10.1590/S0103-56652010000200007

Curtis, K. T., \& Ellison, C. G. (2002). Religious heterogamy and marital conflict. Journal of Family Issues, 23(4), 551-576. doi: 10.1177/0192513x02023004005

Delatorre, M. Z., \& Wagner, A. (2020). Marital quality: reviewing the concept, instruments, and methods. Marriage \& Family Review, 56(3), 293-216. doi: 10.1080/01494929.2020.1712300

Féres-Carneiro, T. (1987). Aliança e sexualidade no casamento e no recasamento contemporâneo. Psicologia Teoria e Pesquisa, 3(3), 250-261.

Féres-Carneiro, T. (1997). Escolha amorosa e relação conjugal na homossexualidade e na heterossexualidade: um estudo sobre namoro, casamento, separação e recasamento. Psicologia: Reflexão e Crítica, 10(2), 351-368. doi: 10.1590/S0102-79721997000200012

Féres-Carneiro, T. (1998). Casamento contemporâneo: O difícil convívio da individualidade com a conjugalidade. Psicologia: Reflexão e Crítica, 11(2), 379-394. doi: 10.1590/S010279721998000200014

Féres-Carneiro, T., \& Diniz-Neto, O. (2010). Construção e dissolução da conjugalidade: Padrões relacionais. Paidéia, 20, 269-278. doi: 10.1590/S0103-863X2010000200014 
Fincham, F. D., \& Bradbury, T. N. (1987). The assessment of marital quality: A reevaluation. Journal of Marriage and the Family, 49(4), 787-809. doi: 10.2307/351973

Fletcher, G. J. O., Simpson, J. A., \& Thomas, G. (2000). The measurement of perceived relationship quality components: A confirmatory factor analytic approach. Personality and Social Psychology Bulletin, 26, 340-354. doi: 10.1177/0146167200265007

Fowers, B. J., \& Owenz, M. B. (2010). A Eudaimonic theory of marital quality. Journal of Family Theory \& Review, 2, 334-352. doi: 10.1111/j.1756-2589.2010.00065.x

Gana, K., Saada, Y., Broc, G., Koleck, M., \& Cazauvieilh, C. (2016). Dyadic cross-sectional associations between negative mood, marital idealization, and relationship quality. The Journal of Psychology, 150(7), 897-915, doi: 10.1080/00223980.2016.1211982

Gottman, J. M., Driver, J., \& Tabares, A. (2015). Repair during marital conflict in newlyweds: How couples move from attack-defend to collaboration. Journal of Family Psychotherapy, 26(2), 85108. doi: 10.1080/08975353.2015.1038962

Halford, W. K., Markman, H. J., Kline, G. H., \& Stanley, S. M. (2003). Best practice in couple relationship education. Journal of Marital and Family Therapy, 29(3).385-406. doi: 10.1111/j.1752-0606.2003.tb01214.x

Hardy, N. R., Soloski, K. L., Ratcliffe, G. C., Anderson, J. R., \& Willoughby, B. J. (2015). Associations between family of origin climate, relationship self-regulation, and marital outcomes. Journal of Marital and Family Therapy, 41(4), 508-521. doi: 10.1111/jmft.12090

Heckler, V. I., \& Mosmann, C. P. (2016). A qualidade conjugal nos anos iniciais do casamento em casais de dupla carreira. Psicologia Clínica, 28(1), 161-182.

Helms, H. M., Supple, A. J., Su, J., Rodriguez, Y., Cavanaugh, A. M., \& Hengstebeck, N. D. (2014). Economic pressure, cultural adaptation stress, and marital quality among Mexican-Origin couples. Journal of Family Psychology, 28(1), 77-87. doi: 10.1037/a0035738

Heyman, R. E., Sayers, S. L., \& Bellack, A. S. (1994). Global marital satisfaction versus marital adjustment: An empirical comparison of three measures. Journal of Family Psychology, 8(4), 432-446. doi: 10.1037/0893-3200.8.4.432

Karney, B. R., \& Bradbury, T. N. (1995). The longitudinal course of marital quality and stability: A review of theory, method, and research. Psychological Bulletin, 118(1), 3-34. doi: 10.1037/00332909.118.1.3

Knapp, S. J., \& Lott, B. (2010). Forming the central framework for a science of marital quality: An interpretive alternative to marital satisfaction as a proxy for marital quality. Journal of Family \& Theory Review, 2, 316-333. doi: 10.1111/j.1756-2589.2010.00064.x

Kwan, R. W. H., Kwok, S. Y. C. L., \& Ling, C. C. Y. (2015). The moderating roles of parent self-efficacy and co-parenting alliance on marital satisfaction among Chinese fathers and mothers. Journal of Child and Family Studies, 24(12), 3506-3515. doi: 10.1007/s10826-015-0152-4

Ledermann, T., Bodenmann, G., Rudaz, M., \& Bradbury, T. N. (2010). Stress, communication, and marital quality in couples. Family Relations, 59, 195-206. doi: 10.1111/j.17413729.2010.00595.x

Lomando, E., Wagner, A., \& Gonçalves, J. (2011). Coesão, adaptabilidade e rede social no relacionamento conjugal homossexual. Psicologia: Teoria e Prática, 13(3), 95-109.

Mahoney, A. (2005). Religion and conflict in marital and parent-child relationships. Journal of Social Issues, 61(4), 689-706. doi: 10.1111/j.1540-4560.2005.00427.x

Maisel, N. C., \& Karney, B. R. (2012). Socioeconomic status moderates associations among stressful events, mental health, and relationship satisfaction. Journal of Family Psychology, 26(4), 654660. doi: $10.1037 / \mathrm{a} 0028901$

McGoldrick, M., \& Shibusawa, T. (2016). O ciclo vital familiar. In F. Walsh (Org.), Processos normativos da família: Diversidade e complexidade (pp. 375-398). Porto Alegre: Artmed.

Meletti, A. T., \& Scorsolini-Comin, F. (2015). Conjugalidade e expectativas em relação à parentalidade em casais homossexuais. Psicologia: Teoria e Prática, 17(1), 37-49. doi: 10.15348/1980- 
6906/psicologia.v17n1p37-49

Mônego, B. G., \& Teodoro, M. L. M. (2011). A teoria triangular do amor de Sternberg e o modelo dos cinco grandes fatores. Psico-USF, 16(1), 97-105. doi: 10.1590/S1413-82712011000100011

Mosmann, C., \& Falcke, D. (2011). Conflitos conjugais: Motivos e frequência. Revista da SPAGESP, 12(2), 5-16.

Mosmann, C., Wagner, A., \& Feres-Carneiro, T. (2006). Qualidade conjugal: Mapeando conceitos. Paidéia, 16(35), 315-325. doi: 10.1590/S0103-863X2006000300003

Norton, R. (1983). Measuring marital quality: A critical look at the dependent variable. Journal of Marriage and the Family, 45,141-151. doi: 10.2307/351302

Rizzon, A. L. C., Mosmann, C. P., \& Wagner, A. (2013). A qualidade conjugal e os elementos do amor: Um estudo correlacional. Contextos Clínicos, 6(1), 41-49. doi: 10.4013/ctc.2013.61.05

Robles, T. F., Slatcher, R. B., Trombello, J. M., \& McGinn, M. M. (2014). Marital quality and health: A meta-analytic review. Psychological Bulletin, 140(1), 140-187. doi: 10.1037/a0031859

Rosado, J. S., \& Wagner, A. (2015). Qualidade, ajustamento e satisfação conjugal: Revisão sistemática da literatura. Pensando Famílias, 19(2), 21-33.

Scheeren, P., Vieira, R. V. A., Goulart, V. R., \& Wagner, A. (2014). Marital quality and attachment: The mediator role of conflict resolution styles. Paidéia, 24(58), 177-186. doi: 10.1590/198243272458201405

Scorsolini-Comin, F., \& Santos, M. A. (2010). Satisfação conjugal: Revisão integrativa da literatura científica nacional. Psicologia: Teoria e Pesquisa, 26(3), 525-532. doi: 10.1590/S010237722010000300015

Shiota, M. N., \& Levenson, R. W. (2007). Birds of a feather don't always fly farthest: Similarity in big five personality predicts more negative marital satisfaction trajectories in long-term marriages. Psychology and Aging, 22(4), 666-675. doi: 10.1037/0882-7974.22.4.666

Silva, I. S., \& Frizzo, G. B. (2014). Ter ou não ter? Uma revisão da literatura sobre casais sem filhos por opção. Pensando Famílias, 18(2), 48-61.

Silva, P. O. M., Trindade, Z. A., \& Silva Junior, A. (2012). As representações sociais de conjugalidade entre casais recasados. Estudos de Psicologia (Natal), 17(3), 435-443. doi: 10.1590/S1413294X2012000300012

Spanier, G. B., \& Cole, C. L. (1976). Toward clarification and investigation of marital adjustment. Journal of Sociology of the Family, 6, 121-146.

Sternberg, R. J. (1986). A triangular theory of love. Psychological Review, 93(2), 119-135. doi: 10.1037/0033-295X.93.2.119

Stroud, C. B., Meyers, K. M., Wilson, S., \& Durbin, C. E. (2015). Marital quality spillover and young children's adjustment: Evidence for dyadic and triadic parenting as mechanisms. Journal of Clinical Child \& Adolescent Psychology, 44(5), 800-813. doi: 10.1080/15374416.2014.900720

Unger, D., Sonnentag, S., Niessen, C., \& Kuonath, A. (2015). The longer your work hours, the worse your relationship? The role of selective optimization with compensation in the associations of working time with relationship satisfaction and self-disclosure in dual-career couples. Human Relations, 68(12), 1889-1912. doi: 10.1177/0018726715571188

Vater, A., \& Schröder-Abé, M. (2015). Explaining the link between personality and relationship satisfaction: Emotion regulation and interpersonal behaviour in conflict discussions. European Journal of Personality, 29, 201-215. doi: 10.1002/per.1993

Wagner, A., Mosmann, C. P., Scheeren, P., \& Lvandowski, D. C. (2019). Conflict, conflict resolution and marital quality. Paidéia, 29(e2919). doi: 10.1590/1982-4327e2919

Financiamento: O presente trabalho foi realizado com apoio da Coordenação de Aperfeiçoamento de Pessoal de Nível Superior - Brasil (CAPES) - Código de Financiamento 001. 
Participação dos autores: a) Planejamento e concepção do trabalho; b) Coleta de dados; c) Análise e interpretação de dados; d) Redação do manuscrito; e) Revisão crítica do manuscrito.

M.Z.D. contribuiu em a,b,c,d; A.W. em a,e.

Editora científica responsável: Dra. Cecilia Cracco 